\title{
Maquillar los cuerpos / Transmutar en movimiento: Reflexiones acerca de las reelaboraciones de la danza butoh y sus máscaras*
}

MAKEUP BODIES / TRANSMUTE IN MOVING: REFLECTIONS ON REMAKES OF BUTOH DANCE AND IT'S MASKS

MAQUILHAR OS CORPOS / TRANSMUTAR EM MOVIMIENTO: REFLEXÕES ACERCA DAS REELABORAÇÕES DA DANÇA BUTOH E DAS SUAS MÁSCARAS

\section{Patricia Aschieri**}

Cuadernos de Música, Artes Visuales y Artes Escénicas

/ Volumen 10 - Número 1 / enero - junio de 2015 /

ISSN 1794-6670/ Bogotá, D.C., Colombia / pp. 95-113

Fecha de recepción: 26 de agosto de 2014 | Fecha de aceptación: 24 de octubre de 2014 | Disponible en línea: 29 de mayo de 2015. Encuentre este artículo en http:// cuadernosmusicayartes.javeriana.edu.co/ doi:10.11144/Javeriana.mavae10-1.mctm

* Artículo de investigación ${ }^{1}$

* *a autora es bailarina butoh y profesora e investigadora de la Facultad de Filosofía y Letras de la Universidad de Buenos Aires y de la Universidad Nacional de Tres de Febrero. 


\section{Resumen}

La danza butoh suele identificarse con el uso de pintura blanca sobre los cuerpos. Sin embargo, las reelaboraciones de esta expresión dancísticoteatral de la vanguardia japonesa, en Argentina, presentan cierto desvanecimiento de esta característica. Casi sin maquillaje, los cuerpos conservan cada vez más los rasgos que los individualizan y particularizan. Para su estudio desarrollaré, desde una perspectiva fenomenológica, los conceptos de transmutación somática o corporizada e imaginación sensorial. Describiré, a partir de los resultados de la etnografía realizada para mi tesis doctoral, los rasgos de las trayectorias corporales previas de los performers que inciden en las reelaboraciones.

Palabras clave: danza butoh; máscara; performance, transmutación; imaginación corporizada

\section{Abstract}

Butoh dance is usually associated with the use of white paint over the bodies. However, the remakes of this theatrical-dancing expression of Japanese avant-garde in Argentine exhibit some fading of this feature. Almost without makeup, bodies increasingly preserve the traits that individualize and particularize them. I propose in this paper a reflection on the possible meanings of the absence or disappearance of makeup. To do this, I am going to develop, from a phenomenological perspective, the concepts of somatic or embodied transmutation and sensory imagination. I am going to describe, based on the results of the ethnography done for my doctoral thesis, those features of the previous body trajectories of the performers that have an impact on in the remakes.

Keywords: Butoh dance; mask; performance; embodied transmutation; embodied imagination

\section{Resumo}

Normalmente a dança butoh identifica-se pela pintura dos corpos com tinta branca. Porém, as reelaborações desta expressão dança/teatro da vanguarda japonesa na Argentina, apresentam um certo desvanecimento desta característica. Quase sem maquilhagem os corpos preservam cada vez mais os traços que os individualizam e particularizam. Eu proponho-me neste trabalho, refletir acerca dos possíveis significados da sua ausência ou desvanecimento. Para isso desenvolverei, desde uma perspetiva fenomenológica, os conceitos de transmutação somática ou corporizada e imaginação sensorial. Descreverei a partir dos resultados da etnografia realizada para a minha tese de doutoramento, las características das trajetórias corporais prévias dos performers que ecoam pondo-se em manifesto nas reelaborações.

Palavras-chave: dança butoh; máscara; performance; transmutação somática ou corporizada; imaginação corporizada 
La máscara comunica la incertidumbre y la amenaza de cambios súbitos, imprevisibles y tan imposibles de soportar como la muerte. Su irrupción libera lo que uno había encadenado para mantener en la estabilidad y en el orden.

Georges Bataille, Le Masque

\section{INTRODUCCIÓN}

Surgida en el Japón de la posguerra, la danza butoh, se origina en un momento de fuerte y violento contacto entre Oriente y Occidente, apoyándose y actualizando sus propias tradiciones performativas en consonancia con los nuevos tiempos históricos y en contacto con nuevas fuentes de estéticas e ideas. Su contexto de surgimiento ha sido descrito como "una explosión brutal atómica y epistemológica", que hizo que los artistas e intelectuales japoneses y extranjeros repensaran el cuerpo a partir de una discusión sobre la identidad, la particularidad cultural y las posibles estrategias políticas de supervivencia (Greiner, 2005).

Entre sus "impulsos originarios", se menciona la intención de "atacar o contrarrestar los efectos de la occidentalización" tratando "de recobrar el nexo tradicional entre el hombre y la naturaleza" (Lizarazo, 2000). No obstante esta actitud de resistencia a la extranjerización, las expresiones de la danza butoh también integraron el llamado teatro Angura de los años sesenta y setenta (una suerte de underground japonés), considerado como parte de un proceso que continúa "las contaminaciones culturales" (Greiner, 2005) que habían comenzado en los primeros años de la Restauración Meiji y que se radicalizaron en la posguerra. En esta línea, Nario Goda, crítico e historiador japonés de la danza, afirma que butoh es "una mezcla internacional de elementos" (Horton Fraleigh, 1999, p. 173)² conectados a través de una pregunta: ¿qué es el cuerpo?

A partir de la década del setenta, la danza se reterritorializa en Europa, Estados Unidos, América del Sur y los países del Este. En suma, podemos afirmar que, en su desarrollo y desde sus inicios hasta sus posteriores reelaboraciones, estuvo signada a remitirse a una zona de intervalo -un in between- que ha involucrado el encuentro de representaciones del cuerpo provenientes de marcos culturales diferentes.

Butoh es un tipo de performance cultural particular que, siguiendo las definiciones de Victor Turner (1986), podría caracterizarse como "género liminoide" (p. 110). En contraste con el fenómeno liminal propio de los rituales de pasaje, los géneros liminoides serían "plurales, fragmentarios y experimentales", pues se trata de géneros secularizados que constituirían una especie de metalenguaje concebido para hablar de lo cotidiano, que podría incluso llegar a ser "subversivo" (p. 110). Turner señala que el fenómeno "liminoide", si bien puede ser colectivo, es característicamente producido por individuos conocidos o específicos que pueden tener efectos colectivos. Dentro de estos géneros incluye ciertas corrientes artísticas, destacando que estas contienen capacidades simbólicas y lúdicas que receptarían cierto "tono sagrado". En este sentido, la danza butoh, como "género liminoide", tiene propiedades quas³ (Turner, 1986) litúrgicas, como pueden ser el despojo, la atmósfera onírica o su característica de ser considerada una suerte de "meditación en movimiento".

Este carácter ritual ha sido señalado por muchos artistas. Grotowski, por ejemplo, la ha definido en términos de la recuperación de una experiencia perdida. Dice textualmente: 
La búsqueda de la forma más antigua de arte, donde el ritual y la creación artística permanecían unidas. Donde la poesía era canción, la canción encantamiento, y el movimiento era danza (Osinski, Zbigniew, 1991, p. 111).

En la década del ochenta, en el ámbito local argentino, Susana Torres Molina la puso en juego como parte de las exploraciones para sus espectáculos. En sus palabras se trata de

Una técnica muy expresiva, fuerte, conmocionante. Los cuerpos desnudos, o casi, totalmente maquillados de blanco se mueven como seres que están más allá de la vida y de la muerte.

(Latin American Theatre Review. Spring, 2002, p 91)

Precisamente entre estas características que la ubican como género liminoide se encuentra el uso de la pintura blanca sobre los cuerpos. Aún casi desnudos, los bailarines se cubren completamente para sus espectáculos como una suerte de enmascaramiento ritual, produciendo en los espectadores un efecto de extrañamiento que oscila entre la fascinación y la repulsión. Níveos cuerpos en movimiento, apenas reconocidos, gesticulan de maneras olvidadas, experimentan temblores hace tiempo domesticados, miran abiertos hacia otros mundos mucho más íntimos y, tal vez por ello, universos lejanos, excepcionales, raros y casi increíbles.

A partir de los resultados de mi etnografía ${ }^{4}$ he identificado que entre los butokas argentinos la práctica de cubrir sus cuerpos tiene diversas interpretaciones y que, incluso, asistimos a un cierto desvanecimiento de su uso. Así, los cuerpos aparentemente desenmascarados comienzan a conservar cada vez más los rasgos que individualizan y caracterizan los rostros $y$, consecuentemente, los gestos parecen recuperar algo de su expresión cotidiana, mientras que los movimientos y las partes corpóreas se vuelven un poco más reconocibles.

"Si [como sostiene Lévi-Strauss (1997)] la máscara niega tanto como afirma, si está hecha de aquello que dice pero también de lo que excluye" (p. 124), en el presente artículo me propongo reflexionar acerca de los posibles significados de su uso, ausencia o desvanecimiento en el espacio traduccional argentino. Para ello, propongo la noción de transmutación corporal o somática. El uso original de la palabra transmutación proviene de la alquimia y hace referencia al proceso de obtención de oro a partir de otros metales. Desde la psicología, Carl Jung (1989) ha retomado este término y ha extendido su comprensión como un tipo de operación simbólica de muy amplio espectro ${ }^{5}$. En este mismo sentido y en el contexto de las relaciones interculturales, Daryush Shayegan (2008), filósofo iraní sensible a las tensiones Oriente-Occidente, definió la transmutación como un proceso que se lleva a cabo mediante la imaginación, a partir de la apertura de un espacio en el que los conceptos fundadores "viajan de una cultura a otra" y en el que "un símbolo puede sustituir a otro sin rupturas, sin degradarse en el campo de la alegoría" (p. 107).

Por mi parte, sostengo que la transmutación abarcaría el proceso fenomenológico en el plano pre-objetivo (Merleau-Ponty, 1975, p. 99) que operaría en la experiencia. Es decir, como un tipo de encuentro encarnado que acontece al ponerse en juego técnicas provenientes de marcos culturales disímiles y que incluye el poder integrador de la imaginación en la experiencia corporal como elemento cognoscitivo.

Como bailarina butoh y por ello parte del $\mathrm{campo}^{6}$, me interesa deslizar una pregunta acerca de si en nuestras reelaboraciones producimos mutaciones inesperadas que provocan variaciones, surgidas estas sin necesidad de establecer un vínculo sustancial con su antecedente- en este caso, el butoh, que podríamos caracterizar como "originario"-. En términos de Jameson (1991), la pregunta es si al producir ciertas modificaciones originamos una "ruptura 
en las cadenas de significantes", o, si por el contrario, con, en y desde los movimientos de nuestras danzas vivenciamos verdaderos procesos transformadores en los que se produce una comprensión que pone en juego un tipo de imaginación corporizada o una "imaginación sensorial" y despierta nuevas zonas, espacios o ritmos corporales para bailar.

Al referir a la imaginación sensorial considero los aportes de Csordas (1993) quien, desde una perspectiva fenomenológica, la ha definido en tanto imaginación que involucra todos los sentidos y no solo la vista, que es la que habitualmente se pondera (p. 143). Es decir, una imaginación que afecta tanto al tacto, como al gusto, el olfato, el oído y la vista. Propongo incluir el sentido cenestésico en el concepto de imaginación sensorial o corporizada, que comprende "el dolor, la orientación en el espacio, el paso del tiempo y el ritmo" (Feldenkrais, 1980, p.40)7.

Ello es así en la medida en que las sensaciones internas de espacio, tiempo y ritmo son sumamente relevantes en el momento de considerar la experiencia de movimiento que proponen las distintas técnicas corporales en general, y en especial la vivencia de la corporalidad que involucra la danza butoh.

En el presente trabajo abordaré, en primer lugar, una perspectiva crítica de los problemas vinculados a los encuentros interculturales en las artes escénicas, iniciando con una discusión sobre la circulación de los bienes culturales en el actual contexto de globalización de los intercambios. En segundo lugar, daré cuenta de los procesos de reelaboración y significación en torno a la danza butoh en Argentina, concentrándome especialmente en aquellos aspectos concernientes al uso de la máscara. Por último y a la luz de estas descripciones, analizaré los procesos de lo que defino como transmutación encarnada, destacando la presencia de aquellos elementos que tienden a la reproducción de rasgos asociados con paradigmas de movimiento y expresión, vinculados a las escuelas teatrales y dancísticas en las que hemos sido socializados los performers.

\section{INTERCULTURALISMOS Y MULTICULTURALISMOS EN LAS ARTES ESCÉNICAS}

Es justo decir que en el mundo globalizado la circulación de bienes culturales tiende a producir reelaboraciones interesantes, en un constante encuentro con símbolos provenientes de diferentes hermenéuticas. Una libertad de elección de recursos, técnicas y prácticas que ponen en juego poéticas de relación siempre inéditas y que pueden transmutarse al infinito, configurando nuevos territorios del ser.

Una revisión crítica hecha por Radka Neumannova (2007) sugiere que la globalización es un proceso ambiguo y complejo que ha dado lugar al surgimiento de una diversidad de políticas multiculturalistas que se mueven entre teorías liberales, por un lado, y posiciones relativistas, por el otro. Las primeras las ubican como modelos de defensa cultural que tienen su fuente en los derechos universales del individuo. Este tipo de enfoques- señala la autorapromueven un tipo de pluralidad cultural en la que cada cultura es concebida como unidad cerrada y en la que se perpetúan estereotipos y diferencias. En contraste, las segundas han demostrado que el concepto de Estado-nación liberal ha ignorado la concepción de la cultura como un sistema basado en una multiplicidad de relaciones y significados que trascienden las propias fronteras del Estado-nación.

Desde un enfoque antropológico, el ya clásico trabajo de Terence Turner ha señalado que la noción de multiculturalismo involucra peligros tanto teóricos como prácticos en la medida 
en que tiende a equiparar o "fusionar el concepto de cultura con el de identidad étnica" (1993, p. 411). En este sentido, comprende "el riesgo de esencializar la idea de cultura como una propiedad de un grupo étnico o de raza" (1993, p. 411); corre el peligro de "reificar la cultura como entidad separada, sobre-enfatizando sus límites y mutuas distinciones" (1993, p. 411). Advierte además, que:

Tratar a la cultura como el bagaje de un grupo étnico tiende a fetichizarlos en formas que los ponen más allá de ser alcanzados por análisis críticos, y consecuentemente más allá de la antropología. (1993, p. 412).

En esta dirección y dado que este estudio es sobre las reelaboraciones de la danza butoh, son pertinentes las discusiones acerca del Orientalismo, definido por Eduard Said (2002) como una disciplina académica a partir de la cual Occidente convierte a Oriente en objeto de conocimiento. El Orientalismo sería para este autor una:

Forma de pensamiento que separa ontológica y epistemológicamente a Oriente [y que] se construye como una proyección del poder de Occidente sobre Oriente para organizar un discurso que estuviera al servicio del poder colonial [y así] dominar, reestructurar y tener autoridad sobre lo Oriental. (p. 21)

Como consecuencia, Oriente fue homogeneizado y convertido en un espacio estático e invariable, oponiéndolo a una visión de Occidente dinámica y heterogénea. Estos planteamientos recibieron la crítica del campo de los llamados Estudios Subalternos, que precisamente la obra de Said contribuyó a inaugurar (Turner, 1994). Por un lado, se le cuestionaron aspectos de índole metodológica. Alexander Macfie (2000) le reprochó que, desde una perspectiva foucaultiana, el procedimiento que utilizó era incorrecto, en tanto las obras analizadas por Said pertenecen a "epistemes distintas"8. Por otro lado, su consideración de un Oriente estático e invariable también recibió fuertes críticas. Según Homi Bhabha (2002), esta conceptualización constituye un artilugio mediante el cual se expresa la parte por el todo, que es la misma actitud esencialista que Said denuncia y, en consecuencia, obstaculizaría la apreciación del hibridismo y la heterogeneidad que sin duda fueron parte de la configuración del poder colonial. En esta misma línea, James Clifford (2001) criticó el concepto mismo de Orientalismo, dado que estos análisis dicotomizaron y esencializaron lo que en realidad constituía un continuo entre Oriente y Occidente.

Esta caracterización de Oriente como un bloque inamovible y monolítico supuso análisis binarios de los que resultaron versiones homogéneas, sin variaciones, multiplicidad o diferencias tanto de Occidente como de su contraparte. No obstante, como ha señalado Maxime Rodinson (1989), el Occidentalismo no debió haber sido la respuesta al Orientalismo.

Como efecto de estas críticas, autores como José Bizerril (2007) prefieren el término culturas asiáticas para referirse a las reelaboraciones de prácticas como el tao en el contexto brasileño. No obstante, considero que, en el caso de la danza butoh en Argentina, las categorías oriente y oriental continúan siendo operativas y descriptivas en tanto formas 'nativas' de caracterizar este tipo de experiencias. Dicha evaluación considera no solo la experiencia de trabajo de campo de este estudio, sino también los análisis de otra investigación en la que he participado ${ }^{9}$, que ha demostrado que Oriente es una categoría ampliamente legitimada entre los actores sociales del campo de las artes escénicas de la ciudad de Buenos Aires (Aschieri y 
otros, 2012). Soy consciente de la necesidad de poner en el centro del análisis las producciones culturales locales específicas.

Lejos de querer profundizar las fetichizaciones orientalistas, mi análisis procura describir las traducciones que suscita 'lo oriental' en su especificidad local, comprendiéndola como parte de un entramado de relaciones de poder históricamente mediadas.

Como parte de los procesos de globalización característicos de la llamada posmodernidad, a partir de la década del setenta las influencias e intercambios en el ámbito de las artes escénicas también se acrecentaron a nivel mundial ${ }^{10}$. Erika Fischer-Lichte identifica esta tendencia como una relación consciente y productiva con elementos de culturas teatrales extranjeras, cuya función se vincularía, sobre todo en algunos directores, con la creación de "un lenguaje universal del teatro [que facilita] la comunicación entre los miembros de diversas culturas" (1994, p. 50).

Retomando el modelo de relaciones culturales desarrollado por Kirsten Hastrup para analizar la relación entre cultura y tradición, Patrice Pavis (2000) propone cuatro casos de intercambio cultural en la práctica teatral. El primero consiste en lo que ella denomina islas culturales, y se refiere a un tipo de relación que se da por la separación entre las prácticas, como la que existe entre una pieza de teatro noh y una de la Comedia Francesa. El segundo tipo es el pluralismo cultural, en el que se ponen "en contacto y en competencia", en un mismo espectáculo, dos producciones de origen y estilo diferentes, tratando de que no aparezcan separados sino como parte de un solo espectáculo (p. 278). El tercero, la criollización cultural, implica una mezcla de fuentes y tradiciones que, en el cruce, involucran la producción de una nueva cultura (un ejemplo sería Derek Walcott o Werewere Liking). Por último, el multiculturalismo, en el que cada cultura refleja la complejidad y la variedad de una sociedad global que 'absorbe' todas las influencias sin sucumbir a una en particular. No se trataría de un cruce sino más bien de una confluencia o fusión, como es el caso de Theatrum Mundi, de Eugenio Barba (p. 279).

Estas clasificaciones realizadas por Pavis hacen referencia al tipo de relaciones que se establecen entre las distintas producciones estéticas, pero no atienden a los vínculos que se establecen entre las personas que realizan estas experiencias. Al respecto me interesa retomar particularmente los desarrollos de Richard Schechner (1994), antropólogo, director y dramaturgo, quien advierte que los intercambios deberían darse "sobre la base de equivalencias" (p. 61) y no entre géneros y culturas. Si bien reconoce que el interés de los artistas por los géneros tradicionales es genuino, éste conllevaría, en muchos casos, "una marca de exotismo y primitivismo" (p. 60). Siguiendo su perspectiva, sería preciso realizar experiencias con artistas de amplio conocimiento en tradiciones escénicas, como el kathakali, pero que estén comprometidos con el teatro moderno antes que con el arte tradicional.

Por último, una perspectiva de los estudios en Prácticas Escénicas que ha tenido amplia difusión en nuestro medio local argentino (y entre muchos de los performers de danza butoh en particular) es la Antropología Teatral, del director y dramaturgo Eugenio Barba (1994). Este enfoque constituye una aproximación al estudio de principios técnicos corporales 'universales', que se encontrarían presentes en la actuación de los performers -independientemente de la cultura dentro de la que estos se practiquen-. Estos principios (entre los que se encuentran la oposición de contrarios y la ley del equilibrio y desequilibrio) no estarían ligados a formas codificadas o determinadas (a modo de pasos coreográficos, por ejemplo), sino que tendrían la característica de ser 'pre-expresivos'. Constituyen lo que Barba caracteriza como una 'segunda naturaleza', que sería aquella que el actor construye para organizar su comporta- 
miento corporal, desarrollar su presencia en el escenario y potenciar su 'energía'. Es decir, se trata de principios que subyacen al uso de los cuerpos. La Antropología Teatral ha explorado fundamentalmente las culturas de la representación de China, India y Japón, y es en gran medida responsable por la difusión, a través de seminarios, talleres, charlas, publicaciones y espectáculos, de estos saberes -ya descontextualizados de su tradición de origen- en Europa y América ${ }^{11}$. Eugenio Barba y su grupo el Odin Teatret han visitado nuestro país en muchas oportunidades (la primera en 1971), dejando huella en muchos performers argentinos ${ }^{12}$.

Si bien comparto la solicitud realizada por Schechner respecto de una "reciprocidad armónica", que implica el establecimiento de intercambios entre artistas, unidos por intereses y preocupaciones comunes, entiendo que también es necesario considerar las relaciones de poder que se hallan implícitas en la constitución de los "hábitats de significado", generados por la existencia de "conexiones transnacionales"13 (Hannerz, 1998, p. 48). En esta dirección, a continuación describiremos los modos en que los performers van armando sus vínculos experienciales y discursivos con la práctica de maquillar y enmascarar sus cuerpos de blanco.

\section{LO VISIBLE DE LO INVISIBLE}

La danza butoh llega a Argentina en 1986 de la mano de Kazuo Ohno, quien presentó sus espectáculos "La Argentina" y "Mar Muerto" bajo la dirección de Tatsumi Hijikata (quien falleció ese mismo año), en el Teatro General San Martín de la ciudad de Buenos Aires. Cabe destacar el particular momento que vivía nuestro país, aún convulsionado, conmovido y a muy poco tiempo de recuperar la democracia. Si bien años antes ya habían comenzado los intercambios interculturales dentro de las artes escénicas argentinas, estos procesos se habían interrumpido dramáticamente a partir de las sucesivas dictaduras militares ${ }^{14}$. En 1983 eso cambió y hubo una explosión de nuevas poéticas. Los artistas salieron a la calle, ocuparon el espacio público, abrieron nuevos escenarios para actuar y bailar, combinando, mixturando y explorando con nuevos lenguajes. La danza butoh conquistó a los espectadores argentinos y también a algunos artistas que viajaron para formarse y traerlo luego a nuestro país. Pueden mencionarse las tempranas experimentaciones, en el ámbito local, de dos dramaturgas: Susana Torres Molina, con su puesta de "Amantíssima" (1988) y Marielouise Alemann, con "Esperanto" (1995). Las primeras performances propias del género butoh argentino fueron Tango Butoh (1994), de Gustavo Collini y Talek (1997), de Rhea Volij. A partir de entonces y con un ritmo que se aceleró en los últimos 15 años, el género ha ido creciendo y ha consolidado un espacio propio de producción en Argentina.

Más allá de las interpretaciones propias de su contexto de origen ${ }^{15}$, me interesa describir y reflexionar acerca de los distintos modos en que los performers argentinos experimentan el hecho de pintar sus cuerpos. Por un lado, están aquellos bailarines y bailarinas que incorporan la pintura porque se sienten "más protegidos", "resguardados del afuera", posibilitados a ser "otra cosa". “La máscara es así, símbolo de la alteridad: conecta con 'lo otro', lo que está oculto, cubierto o protegido por otra máscara" (Matoso, 2001, p. 67). La pintura blanca produce, en este sentido, un doble efecto de enmascaramiento-desenmascaramiento, proporcionando al bailarín una corporeidad diferente que permite que caiga aquello que permanece oculto tras la máscara cotidiana de la identidad individual y social. En esta dirección, los bailarines reconocen que pueden lograr "más transformación todavía" o que, al "perder el rostro que uno ve 
todos los días en el espejo", logran 'sorprenderse' a sí mismos. Por otro lado, la pintura como máscara también posibilita liberar otros aspectos ocultos de su condición humana. Una transformación que trae consigo una potencia de sensaciones que los hace sentir realmente vivos y convertirse realmente en un árbol más, en un insecto o en una piedra volcánica, por mencionar solo algunos de los ejemplos que los bailarines refirieron en las entrevistas que les realicé. En síntesis, los cuerpos se cubren o velan con el objetivo de realizar un ritual de ocultamiento de la personalidad, lo que podríamos describir como una ceremonia de enmascaramiento del yo, un procedimiento de conversión que suele percibirse como un facilitador para alcanzar lo que los butokas identifican como 'la caída del ego'.

Asimismo, se encuentran los bailarines que utilizan el enmascaramiento como un recurso para 'meterse en el mundo del butoh' o como una forma de reafirmación e identificación que les permite sentirse parte de un colectivo. No obstante este compromiso, hay quienes señalan razones económicas que obstaculizan el uso de la pintura blanca, refiriendo que es muy cara y que hay que tener plata para poder usarla siempre. Puede ser por esta razón que deciden reemplazarla con otro tipo de materiales como la arcilla o el barro. A este respecto es importante señalar que la mayoría de los bailarines locales, por lo general, no recibe subsidios para la realización de sus espectáculos, así que deben auto-financiarse ${ }^{16}$.

En otros casos incluso prefieren no usar nada. Ciertos butokas dicen que pintarse es incómodo, ya que en muchas oportunidades deben bailar en lugares que no poseen las instalaciones adecuadas para este tipo de despliegues porque carecen de agua, espejos y baños. También hay bailarines que le restan toda relevancia, argumentando que no es necesario estar de blanco para ser butoh; la pintura puede no estar. Incluso, algunos llegan a reconocer que esta no es tan importante y que no hace al sentido de la danza.

En suma, en el discurso, los bailarines refieren que la máscara le da al actor-bailarín la posibilidad de desconocerse, de liberarse del individuo y de su propia subjetividad, y de poner su cuerpo, un cuerpo, un otro cuerpo en danza, como una especie de técnica de vaciamiento. El enmascaramiento también facilita la multiplicación de las identificaciones. La máscara convoca otros sentidos, no solo del performer sino también del espectador, que puede dejar de ver a un individuo que danza para empezar a comprender, resonando mimética y sensiblemente, al cuerpo otro y transformarse en él. Olvidarse de sí para perderse en el ensueño de un universo colectivo, relegado, casi perdido y ajeno de sensaciones y percepciones inaugurales ${ }^{17}$.

En el pensamiento japonés, el uso de máscaras involucra la materialización de una oposición conceptual ura-omote-derecho/revés; lo que se ve/lo que se oculta- (Sato, 2008). Precisamente, conmoverse entre opuestos es una de las características centrales del mundo metafórico y, más importante aún, del movimiento y del sentido cenestésico que define a la danza butoh $^{18}$. En esta dirección resulta relevante reflexionar acerca del contexto de interpretación en el que se pone en juego el uso o no uso del maquillaje sobre los cuerpos.

\section{LO INVISIBLE DE LO VISIBLE}

Hablar de máscaras o de procesos artísticos quasi rituales de enmascaramiento supone considerar brevemente los contenidos de la noción de persona. El clásico trabajo de Marcel Mauss ha destacado para Occidente la presencia de una significación moral y social, en contraposición a su ausencia en las sociedades no occidentales. En palabras del autor: 
El recorrido es complejo, de una simple mascarada se pasa a la máscara, del personaje a la persona, al nombre, al individuo: de este se pasa a la consideración del ser con un valor metafísico y moral, de una conciencia moral a un ser sagrado, y de este a una forma fundamental del pensamiento y de la acción. (Mauss, 1979, p. 333)

Mauss señala que, en el origen, máscara y persona estaban entrelazadas indisolublemente, ${ }^{19}$ a partir de una significación de persona asociada a la noción de personaje como representación de una entidad colectiva (en tanto rol o posición que un individuo ocupa en la vida familiar, social o religiosa). Más tarde, la noción de persona del derecho romano transforma su significado en tanto hecho de la ley. Esta idea de persona, posteriormente, continúa desarrollándose con los aportes de los pensadores griegos, particularmente a partir de la filosofía de los estoicos, para quienes la idea de persona incluía tanto a la máscara -en el sentido de apariencia o fachada construida para otros- como a la persona consciente, responsable y libre -una concepción más ligada a la intimidad-. El mundo cristiano le da una base metafísica, considerando la unidad de la persona y la Iglesia respecto de la unidad de Dios. La noción de unidad de la persona involucrará la idea de un cuerpo y un alma y, concomitantemente, la conciencia y la racionalidad del acto. La última transformación está vinculada con su mutación como categoría del ser, en tanto conciencia psicológica e individual.

En suma, con el desarrollo de la noción de persona como hecho moral, la necesidad de la máscara como objeto físico desaparece y su utilización queda confinada al ámbito del teatro. En un largo proceso que va desde el derecho romano, pasando por el cristianismo y luego la filosofía moderna, la noción de persona fue separándose de la noción de máscara a la que originariamente se encontraba ligada, en total correlación con el proceso de individuación y dicotomización cuerpo/mente, ya suficientemente referida y descrita desde distintos ángulos y por diversos autores. La mente se asoció a la razón, la conciencia, la espiritualidad y la interioridad, y el cuerpo se cristalizó como impedimento, como una desautorizada representación temporal de lo que sería el verdadero ser, algo exterior a la auténtica persona. El atributo de la máscara como manifestación materializada de la identidad fue perdiendo su potestad como representación valedera de la persona y quedó asociada a la idea de la representación y, con ello, cada vez más cerca de lo falso, de la impostura. Hay infinidad de ejemplos en los dichos y frases que plagan nuestro sentido común y que dan cuenta de ello.

Para un análisis de los sentidos y usos de la máscara o de la práctica de enmascaramiento entre los performers argentinos, presentaré a continuación -sintéticamente y de modo analítico-algunos de los rasgos que podemos encontrar en el uso ritual de máscaras y en la máscara como elemento teatral. Para ello, tendré en cuenta, entre otros, los desarrollos de Jaques Lecoq (2005), uno de los dramaturgos que más sistemáticamente ha tratado los usos de la máscara -en particular de la máscara neutra ${ }^{20}$ - en la formación y entrenamiento de actores. El siguiente cuadro pretende dar cuenta de las principales características y diferencias entre ambas dimensiones de uso: 


\begin{tabular}{|c|c|}
\hline Máscaras en el ritual & Máscara como elemento teatral \\
\hline $\begin{array}{l}\text { No hay separación entre lo que } \\
\text { es representado y lo concebido } \\
\text { como real. Resuelve una tensión } \\
\text { entre la identidad personal y el } \\
\text { personaje. }\end{array}$ & $\begin{array}{l}\text { Separación entre actor y personaje. Forma parte de } \\
\text { diversas técnicas teatrales destinadas a que el actor } \\
\text { se despoje de su persona y construya personaje (la } \\
\text { máscara neutra de Lecoq por poner uno de los más } \\
\text { importantes ejemplos). }\end{array}$ \\
\hline $\begin{array}{l}\text { No hay división entre público y } \\
\text { enmascarados. }\end{array}$ & $\begin{array}{l}\text { La obra teatral se mantiene separada del público (rasgo } \\
\text { que esta cambiando en la actualidad). }\end{array}$ \\
\hline $\begin{array}{l}\text { Está condicionada por su } \\
\text { contexto ritual. }\end{array}$ & $\begin{array}{l}\text { Es un elemento visual que encuentra su sentido } \\
\text { dentro de los límites de la obra. }\end{array}$ \\
\hline $\begin{array}{l}\text { Doble función de encubrir y } \\
\text { mostrar. } \\
\text { Intermediaria entre opuestos }\end{array}$ & $\begin{array}{l}\text { Permite al actor ampliar su capacidad gestual y } \\
\text { postural a partir de conocer y evitar sus hábitos de } \\
\text { movimientos y sus posturas. }\end{array}$ \\
\hline
\end{tabular}

Cuadro No. 1. Atributos máscara de uso ritual y máscara de uso teatral

Desde una perspectiva que contempla su uso ritual, Lévi-Strauss (1997) ha señalado que las máscaras están íntimamente relacionadas con los mitos fundadores de cada grupo y con los rituales de iniciación cuando se accede a un nuevo estatus. Desde su punto de vista, cada máscara posee un mensaje en oposición a otra máscara, donde una connota y otra vehiculiza, cumpliendo funciones sociales o religiosas. Las máscaras asumen en estos ámbitos un poder mediador entre representación y lo representado y entre significado y significante, y también una capacidad de intermediación entre el mundo sobrenatural y el mundo humano. En este sentido, su uso ritual pone de relieve y potencia su capacidad para habitar la ambigüedad, así como su poder de transformación y de metamorfosis ${ }^{21}$.

Considerada como elemento teatral, la máscara permite establecer estereotipos reconocibles, capaces de condensar una serie de significados que serían parte de una personalidad específica -por ejemplo, un personaje fijo en un espectáculo al que se le atribuyen determinadas características, o los personajes de la Comedia del Arte-. Su uso en los entrenamientos estimula la capacidad de ampliar las capacidades gestuales, vocales y de movimiento del actor. Siguiendo a Lecoq, la máscara "filtra lo esencial y deja caer lo anecdótico" (2005, p. 66). Asimismo, permite establecer contrastes y complementariedades entre máscara, formas o posturas corporales y vocales; y adquiere cierta relevancia en la medida en que enfatiza la distinción entre los personajes que la llevan y aquellos que no.

Como hemos mencionado en muchas de las apreciaciones respecto del uso del maquillaje sobre los cuerpos, los performers argentinos destacan que les permite descubrir un cuerpo nuevo, una corporalidad otra que les posibilita la exploración de aspectos a los que tal vez no hubieran accedido sin el proceso de enmascaramiento. Fundamentalmente, los bailarines expresan que el maquillaje les ayuda en el proceso que constituye uno de los pilares de la danza butoh: la caída del ego.

Al respecto, cabe señalar que esta premisa está profundamente asociada a la idea de que no es la persona la que baila, sino que 'es danzada' por otras fuerzas o energías ${ }^{22}$-como suelen reiterar los performers refiriéndose al butoh. La idea de 'bailar sin ego' también está asociada a la consideración de la danza butoh como danza espiritual, no intelectual y, más 
precisamente, una sin pensamientos. En este sentido, la mayoría de los performers expresan sus dificultades a la hora de tratar de no pensar, de 'estar ahí en el momento presente', lograr 'menos discurso mental' y 'aplacar el cerebro'. Para frenar "la fuerza de la cabeza que no deja de funcionar jamás" -como sostiene una practicante- los maestros suelen repetir en los workshops: "dancen sin pensamientos", "dejen los pensamientos de lado", "permitan que las imágenes y los pensamientos fluyan", "no se detengan en ninguno". En sintonía con estas ideas, muchos performers argentinos suelen tener vínculos de intensidad variable con alguna filosofía de raíz budista. Incluso, algunos de ellos dicen que es precisamente gracias a estos contactos que han podido acercarse más profundamente a la comprensión de la danza butoh.

No obstante este 'despojamiento' del yo, es preciso decir que los bailarines señalan enfáticamente que una de las mayores motivaciones que encuentran para elegir la danza butoh es las posibilidades que brinda como medio de exploración y expresión de la subjetividad. Así, en la entrevistas, algunos performers aseguran: "es una danza que me permite expresarme tal cual soy", "busco danzando lo que me define esencialmente desde mi individualidad", "elijo la danza butoh pues hace a la diferencia con los demás, desarrollo mi propia identidad". En suma, me interesa destacar que, en el caso de nuestro butoh local, el requerimiento de 'bailar sin ego', así como la propensión a explorar la identidad del performer como una importante revalorización de la expresión individual, pone en juego marcos interpretativos contrapuestos que generan variadas explicaciones respecto de cuál sería la posición del sujeto que danza, al tiempo que tensiona los contenidos de la noción de persona.

¿Cómo entender entonces los espacios de significación atribuidos a la práctica de enmascaramiento y la identificación de una tendencia a dejar de pintarse los cuerpos? En otros trabajos he subrayado que en las reelaboraciones se ponen en juego diversas interpretaciones discursivas y encarnadas, relativas a las trayectorias corporales de los performers. Defino trayectorias corporales como los espacios experienciales de reelaboración que abarcan el análisis de la relación entre los habitus (Bourdieu, 1991, p. 91) cotidianos y las experiencias de apropiación de un conjunto de prácticas vinculadas al uso y representación del cuerpo y el movimiento-como pueden ser entrenamientos en la forma de habitus dancísticos, teatrales, etcétera-.

En el caso de los butokas argentinos, estas trayectorias corporales están fuertemente conectadas con las artes marciales como el tai chi chuan o el kendo, y también con la Antropología teatral. También con el actor santo de Jerzy Grotowski, con algunas técnicas teatrales para actores propuestas por Stanislavski, así como la danza clásica y contemporánea y el expresionismo alemán, entre otras. Solo para poner un ejemplo, cito el caso de un performer donde puede notarse en qué medida estas influencias tienen relevancia:

No, no sé si [el butoh] tiene mucho de japonés, no sé, los japoneses tienen algunas particularidades... no quiero decir... son muy yang, porque también son muy yin, los japoneses tienen algo de los alemanes, no es casualidad que se hayan aliado en la guerra. $Y$ en la personalidad de los japoneses hay muchas cosas de los alemanes. (...) mi viejo era alemán, y la danza butoh abrevó de la danza expresionista alemana, no solamente de la danza, sino todo el movimiento expresionista europeo, que para mí es fascinante... si a mí me tenés que regalar un cuadro famoso, yo elijo el expresionismo, no elijo ni el impresionismo, ni el clasicismo. El expresionismo primero que todo... y cuando pinto, primero que todo, soy expresionista, si vos ves un cuadro mío decís "pobre pibe, qué le pasa, tiene que ir al Cotolengo", pero los colores y la forma del 
dibujo y todo es expresionista, entonces yo sentía todas esas características de alemán, de japonés. (Actor, 50 años)

Puede apreciarse entonces que los actuales modos de entrenamiento locales están fuertemente atravesados por los paradigmas occidentales de expresión y movimiento. En este contexto es que debemos comprender, en parte, al menos algunas de las valorizaciones de la práctica de enmascaramiento. Por un lado pueden rastrearse, como vimos, ciertas referencias al poder transformador de las máscaras, aunque se trataría de interpretaciones más cercanas a la separación entre el individuo y el personaje, marcando en esta dirección cierta continuidad con las técnicas y usos de la máscara escénica de tradición occidental antes reseñados (por ejemplo, su uso como facilitador para encontrar otro cuerpo a partir del agrandamiento, la exageración, la concentración, etc.). Por otro, apreciamos que se encuentra prácticamente ausente entre los discursos y experiencias de los performers su cualidad como recurso que permite explorar contrastes u oposiciones y que, como mencionamos, es uno de los sentidos más fuertes del uso de la máscara en el contexto de la interpretación escénica japonesa. En este sentido se desvanece también su propensión a profundizar la exploración de la ambigüedad.

Este poder transformador de la máscara como elemento ritual, de metamorfosis de ambigüedad experiencial entre mundos, presente en las artes escénicas japonesas como el Teatro Noh y que ubicaría a la danza butoh como género liminoide, parecería estar experimentando un proceso de debilitamiento. Así, la desaparición del maquillaje y su concomitante condición como facilitador para la exploración de opuestos, así como su potencialidad para habitar "entre mundos", indicaría una disminución de su poder de subversión, una mengua de su poder de cuestionamiento y de interpelación a un estado de cosas de la danza y del mundo.

Sostengo entonces que la capacidad lúdica que pone en juego la imaginación sensorial o corporizada encuentra ámbitos de resistencia en la presencia de proyectos previos más ligados a las trayectorias corporales de los performers. Ello es así debido a que, siguiendo a Gadamer, cuando en la comprensión aparece un primer sentido

El intérprete proyecta en seguida un sentido del todo [y entonces] lee el texto desde determinadas expectativas (...) [por lo que] la comprensión consiste precisamente, en la elaboración de este proyecto previo. (1991, p. 333)

Así, la experiencia fenomenológica, en términos de una transmutación corporal o somática, encuentra interpretaciones y vivencias que involucran en las trayectorias corporales de los bailarines -aunque no solo en ellas ${ }^{23}$ - un fuerte e invisible obstáculo para explorar otros ámbitos posibles del movimiento y la expresión.

En suma, en las formas de su apropiación inciden ciertas tendencias a reproducir aquello que precisamente en ese mismo acto de apropiación/reelaboración se busca rechazar, cambiar o transformar. Como señala Homi Bahbba (2002), la hibridez de ciertas expresiones culturales podría resultar desautorizante para los modelos aunque, no obstante, estos sigan siendo utilizados. Precisamente a la elección de practicar danza butoh de muchos performers argentinos subyace un fuerte rechazo al tipo de experiencias que propone una cotidianidad en la que prima la división entre el cuerpo y la mente, la ponderación de determinados cánones de belleza y la búsqueda del virtuosismo. A partir del análisis de la experiencia de enmascaramiento puede apreciarse que, si bien existen algunas rupturas, también persisten continuidades en algunos sentidos y movimientos que aún permanecen indiscutidos y protegidos por aparentes cambios estéticos o técnicos. 


\section{PARA CONCLUIR: VIVENCIANDO LA MULTIPLICIDAD DE ENMASCARAMIENTOS}

Entiendo que la dimensión corporal abarca el entrecruzamiento de valores y sentidos sociales, culturales y políticos en los que las personas hemos sido socializadas, teniendo en cuenta nuestra siempre dinámica y particular trayectoria corporal. Estos sentidos se ponen en juego -actualizándose la mayoría de veces acríticamente- en los diferentes momentos y actividades a las que nos dedicamos -de expresión, de entretenimiento, de investigación, etc.-, direccionando, lo sepamos o no, nuestras vivencias y experiencias.

He señalado en otro trabajo (2012), a partir del análisis de la producción gestual, que, si bien los performers pueden reconocer amplia y extendidamente en sus discursos el principio de 'ser danzados', aún serían escasas las experiencias que ciertamente lo ponen en acto y, en consecuencia, sus danzas suelen mostrar la presencia de las trayectorias corporales propias de cada bailarín sin poderse apreciar transformaciones significativas en la producción de movimientos. En este sentido, la desaparición del enmascaramiento de los cuerpos estaría en concordancia con estas tendencias. Entonces, se puede señalar una interesante paradoja. Mientras que la danza butoh parecería ofrecer amplios márgenes para el desarrollo de la creatividad -iy es por eso que la elegimos!-, perdurarían ámbitos como el del movimiento o el enmascaramiento de los cuerpos en las prácticas de movimiento y expresión de los bailarines, refractarios a poner en práctica su potencialidad innovadora y disminuyendo, en cierto sentido, su capacidad de interpelación y transformación.

La reflexión que he realizado no pretende conservar, entre los butokas argentinos, el aspecto formal del uso de la pintura blanca y atesorar así la acción concreta de enmascarar los cuerpos, sino proponer una reflexión sobre los juegos de sustituciones que encarnamos. He puesto de relieve aquellas tendencias que obstaculizarían nuestros proyectos estéticopolíticos de transformación tendiente a subvertir cierto orden y convocar lo que considero un aspecto ineludible de la experiencia corporal: la capacidad de agencia. Es decir, teniendo en cuenta la posible presencia de procesos de transmutación, la ausencia de pintura blanca en los cuerpos de los bailarines no excluiría necesariamente la transformación o la emergencia de un estado donde todo se vuelve posible, donde se diluyen las cristalizaciones para dar lugar a las metamorfosis con el advenimiento de otros modos de estar y de ser en el mundo.

Propongo entonces que estemos alerta y sensibles a los procesos de traducción cultural que protagonizamos en nuestras prácticas improvisacionales en escena. Como elemento constitutivo de la danza butoh-aunque incluso negada en la materialidad del maquillaje por las razones que sean-, la máscara debe concretarse en la reflexión de nuestras corporalidades danzantes. Una construcción del gesto a partir de cuerpos dispuestos a bailar su oscuridad, su misterio, su enigma, su impulso secreto e indescifrable. Como butokas, no debemos olvidar, como sugiere Bataille (1970), que al caer una máscara, la muerte irrumpirá súbita e insoportable y que rápidamente vivenciaremos el impulso de incorporar otra máscara. Entonces, más que nunca, nuestros movimientos butoh deben explorar allí, detrás de las múltiples sombras de nuestras huidizas e infinitas máscaras encarnadas. 


\section{NOTAS}

1 Una primera versión sintética se presentó en el III Congreso de Artes en Cruce. Los espacios de la memoria. Facultad de Filosofía y Letras. Universidad de Buenos Aires. Agosto. Año 2013

2 En otros trabajos (Aschieri 2006, 2010, 2013) he descrito críticamente que pueden mencionarse diversas influencias y conexiones con géneros de distintas procedencias, tanto de origen japonés como del teatro y la danza occidental y que abarcan distintos periodos, mostrando o escondiendo estas marcas en sus encuentros y transformaciones. El género butoh tiene raíces en el budismo zen, en las más antiguas tradiciones folklóricas japonesas, en las tradiciones del teatro japonés, y sostuvo un diálogo intenso con distintas expresiones del surrealismo y del expresionismo alemán. Durante la primera mitad del siglo XX, en la ciudad de Tokio, había posibilidades de formación en ballet ruso, flamenco, danza jazz, danza expresionista alemana y técnica Graham, entre otras. Se trataba de cursos cortos y rápidos que no brindaban formaciones sistemáticas en estas técnicas. Muchos artistas de aquellos años confluían en la Academia Ando, donde Tatsumi Hijikata, uno sus padres fundadores, hizo sus primeras experimentaciones en improvisación durante los años cincuenta. Kazuo Ohno, el otro de sus principales creadores, se había graduado de la Escuela Atlética de Japón. Ambos bailarines tuvieron vínculos con la danza expresionista alemana. Por un lado, Ohno, después de quedar conmovido por la danza de Harald Kreutzberg, hizo su entrenamiento con los pioneros de la danza moderna en Japón: con Baku loshii y con Takaya Eguchi, quien se había formado en la escuela de Mary Wigman. Hijikata, por su parte, se formó con Kazuko Matsumura, discípulo de Eguchi.

3 VerTurner (1986)

4 "Subjetividad en movimiento. Reapropiaciones de la danza butoh en Argentina". Tesis doctoral en Antropología. Facultad de Filosofía y Letras. Universidad de Buenos Aires. 2013.

5 Para Jung, la alquimia no es simplemente una etapa previa a la química. Refiere que era insensato intentar hacer oro de las piedras y que los alquimistas nunca lo lograron. Desde su perspectiva, el oro representa la inmortalidad, aquello a lo que tiende realmente la transmutación psíquica humana con el proceso de individuación al testimoniar el sí-mismo, experiencia que conecta al individuo con lo eterno e imperecedero. Tanto en la psicología analítica como en la alquimia, se contacta con el aspecto divino una vez cumplida la gran obra. Es el equivalente a transformar al hombre en espíritu, a actualizar el arquetipo. La piedra filosofal es el instrumento simbólico de regeneración en la consumación de la gran obra de los alquimistas, es la piedra de oro por la que se puede llegar a ser eternamente rico, sano, sabio. La piedra está viva y da vida. El método consiste pues en pasar de la piedra "bruta" (lo inconsciente indiferenciado o materia prima) a la piedra "tallada" (la integración de la conciencia), del alma oscura, al alma iluminada, gracias al conocimiento divino (la gracia). Se trata de "darse cuenta de" (Jung, 1989).

6 Desde 1995 soy performer de danza butoh y he desarrollado actividades como performer, coreógrafa, y docente de esta expresión. A partir de2008 he convertido este campo en mi objeto de estudio antropológico. Esta doble implicancia como 'nativa' e investigadora ha involucrado un constante control de mis supuestos y una profunda reflexión metodológica acerca de la presencia del conocimiento encarnado en la producción de conocimiento. Para un acercamiento a estas discusiones, remito a mis trabajos (Aschieri, 2006b, 2013a, 2013b).

7 Para Michel Bernard (1994), la cenestesia abarcaría dos tipos diferentes de sensibilidad:

La sensibilidad propiamente visceral que Sherrington denominó "interoceptiva" y otra sensibilidad que este autor denominó "propioceptiva o postural," cuyo asiento periférico está en las articulaciones y en los músculos (fuentes de sensaciones kinestésicas) y cuya función consiste en regular el equilibrio y las sinergias (las acciones voluntarias coordinadas) necesarias para llevar a cabo cualquier desplazamiento del cuerpo (p. 28).

8 La crítica enfatiza que, si bien Said había reconocido en sus desarrollos la influencia de la crítica textual de Michel Foucault (en tanto consideró que los textos están insertos dentro de una amplia red de relaciones políticas, sociales y culturales que permiten una aproximación y análisis de otras situaciones), sus interpretaciones incurrieron en el error de aplicar el mismo punto de vista a obras de autores pertenecientes a periodos precapitalistas y capitalistas (como por ejemplo, Esquilo o Chateaubriand). Asimismo, a diferencia de las elaboraciones de Foucault que consideraban a los sujetos como parte de un entramado social que trasciende la personalidad y la subjetividad individual, Macfie (2000) señala que Said otorgó un rol determinante a la biografía y a las situaciones personales.

9 Proyecto de Reconocimiento Institucional “¿Paradigmas corporales en conflicto? La presencia de prácticas de tradición cultural oriental en el proceso de aprendizaje de técnicas de actuación y danza". Dirección: Patricia Aschieri (PRI-03-FFyL-Res-CD-4807-09). 
10 En otro trabajo (Aschieri, 2012 y equipo) hemos descrito con mayor detalle las particularidades de la expansión de las artes de escénicas de tradición oriental.

11 Barba y su grupo implementaron lo que caracterizan como un tipo de "intercambio recíproco" que denominaron "trueque," en el que cada grupo ofrece a otro sus conocimientos. En palabras del dramaturgo:

En el más allá del teatro estaba el "trueque": el intercambio de nuestra presencia teatral -entrenamiento, espectáculos, experiencias pedagógicas- con las actividades de otros grupos teatrales o con grupos de espectadores. No era tan solo la búsqueda de un uso de teatro con formas y en contextos diferentes. Era, sobre todo, la manera de revitalizar a una relación de otra forma deteriorada: el modo de pasar el encuentro con espectadores-fantasma que vienen una noche y después desaparecen, al encuentro con espectadores que, además de ver a los actores, se muestran y se presentan ellos mismos (1988, p. 470).

12 Una perspectiva menos difundida es la "etnoescenología", que sería "el estudio de las prácticas y de los comportamientos humanos espectaculares organizados, en las distintas culturas" (Pavis, 2000, p. 286). El método de análisis etnoescenológico se fundamenta en la semiología y pretende evitar la proyección del modelo reductor del teatro occidental sobre las prácticas espectaculares de distintas culturas, favoreciendo una perspectiva integradora que abarcaría la totalidad de las manifestaciones expresivas humanas, entre las que se mencionan a las dimensiones somáticas, las físicas cognitivas, las emocionales y las espirituales (Pavis, 2000).

13 Con este concepto, Hannerz (1998), retomado a Bauman, intenta superar las limitaciones que supone el sentido determinista del concepto de cultura y propone que cada individuo construye para sí, a lo largo de su vida, un entramado de significados en tanto seres autónomos. Su interés es focalizar una investigación social que considere la agencia, más que la estructura, que induciría a la reproducción. Este enfoque reclama que existe una cultura mundial, caracterizada por la organización de la diversidad y no por la reproducción de la uniformidad.

14 Los intercambios habían comenzado en la década del sesenta y principios los setenta, a partir de la influencia de corrientes que venían desarrollándose en Europa o en Estados Unidos a lo largo de varios años. El Instituto Di Tella (1958-1970) constituyó uno de los más importantes centros de experimentación, cuyas actividades fueron perseguidas por la policía y, sobre todo, por el gobierno de facto de Onganía (1966-1970). Con el recrudecimiento de la situación política, los intelectuales y artistas influidos por la tendencia, a nivel internacional, comenzaron a considerar la intervención política directa. Así, el movimiento de modernización cultural ligado a las vanguardias artísticas fue absorbido por la exigencia de radicalización del compromiso político frente a un régimen autoritario y altamente represivo (Svampa, 2003). Esta situación reordenó el panorama de producción escénica, poniendo en el centro los compromisos ideológicos de los artistas e incentivando, en el caso del teatro, por ejemplo, la elección del realismo y un mayor uso de la metáfora para comunicar veladamente contenidos eminentemente políticos. Solo a partir de la recuperación de la democracia pudieron retomarse algunas de las influencias de los años anteriores, aunque ya combinadas con otras tendencias.

15 Existen distintas explicaciones sobre el rasgo estético que envuelve los cuerpos de blanco. Tal como se explica en el trabajo de Ishikuza Tara (2005), una muy frecuente es que el blanco mostraría la desesperanza de las víctimas de la guerra. Otra hace referencia a que simbolizaría las cenizas de los cuerpos cremados. La versión de Kazuo Ohno sugiere, en cambio, que al comienzo los bailarines se cubrían de blanco como una muestra de la inmadurez de su técnica. Por su parte Motofuji, la mujer de Tatsumi Hijikata, señala que en realidad su marido cubría una herida que había sufrido por un derrame de una caldera cuando trabajaba en una fábrica. No obstante estas interpretaciones, puede decirse con certeza que este tipo de tratamiento de los cuerpos en la escena revela cierta continuidad con las practicas del teatro Kabuki y el teatro Noh que, entre otros, constituyen algunos de los importantes antecedentes que participan en la conformación del butoh en sus orígenes.

16 Esta tendencia podría haberse modificado un poco en los últimos años a nivel nacional a partir de la asignación de un mayor presupuesto a las áreas culturales y de un incremento en cantidad de becas o subsidios. Algunas producciones e investigaciones escénicas ligadas a la danza butoh han recibido apoyo de Prodanza, del Fondo Nacional de las Artes y del Fondo Metropolitano para las Artes, por ejemplo. No obstante, estas son más bien excepcionales.

17 Puede decirse que teatro, danza y ritual comparten un importante rasgo común vinculado a la forma de comunicación que establecen. Se trata de una comunicación perceptual, es decir, de tipo pre-reflexivo, ya que en todos los casos se apela a los sentidos y a las emociones (Citro, 2001). Este tipo de comunicación pre-reflexiva implica una fusión entre el cuerpo del sujeto que percibe y lo percibido, es decir, no existe diferenciación entre sujeto y objeto y por lo tanto, no hay pensamiento reflexivo (Aschieri, 2006). 
18 Una de las nociones medulares de la danza butoh es la de butoh tai. Según Tohiharu Kassai (2003), investigador del Departamento de Psicología de la Sapporo Gakuin University, este término hace referencia a una "actitud física y mental para integrar elementos dicotómicos" como, por ejemplo, consciente/inconsciente, o sujeto/ objeto.

19 Tanto prosópon (palabra griega) y persona (palabra latina) eran vocablos utilizados para designar a la máscara.

20 La máscara neutra es un recurso pedagógico para neutralizar las tendencias a recurrir a la reiteración de los rasgos que particularizan al actor. En este sentido encuentro similitudes con el uso de la pintura blanca sobre los cuerpos como instancia de despojo y austeridad en la expresividad de los bailarines butoh.

$21 \mathrm{El}$ autor describe que las diferencias de estilo entre diferentes clases de máscaras indígenas están en relación con las formas en que los mensajes se oponen entre sí. La construcción de máscaras se encontraría condicionada, en este sentido, por un orden lógico e histórico. Es decir, lejos de ser expresiones espontáneas u originales, siempre constituyen una "replica a otros creadores pasados o presentes, actuales o virtuales. Se sepa o se ignore, nunca se marcha a solas por el sendero de la creación" (Lévi-Strauss 1997, p. 193).

22 La proposición de bailar "sin ego" o "sin yo" es insistentemente referida por los maestros que han visitado nuestro país, quienes lo han referido de diversos modos en los workshops (talleres). Está ligado a la dirección consciente de la energía. Esta puede ser estrechamente canalizada o ampliamente irradiada, y refleja las profundidades de la interioridad, y/o las energías entrelazadas con otros. La llave para moderar la energía entre categorías opuestas y el manejo de la energía ki requeriría entonces el dominio que parte de la conciencia y del auto-conocimiento.

23 Si bien en el movimiento de los performers puede apreciarse la búsqueda de movimientos inéditos para resistir viejos o alcanzar nuevos sentidos, las condiciones de circulación de la danza (formato de transmisión de la técnica, accesibilidad por ubicación geo-económica de nuestro país, incidencia de los medios técnicos de reproducción, tiempo dedicado a los entrenamientos, etc.), debilitan la presencia de aquellos elementos que interpelarían en principio los habitus dancísticos o aquellos socialmente incorporados (Aschieri, 2012).

\section{REFERENCIAS}

Aschieri, Patricia. “Danza Butoh: Cuerpos en movimiento, Cuerpos en reflexión.," en Matoso, Elina, comp. El Cuerpo In- Cierto. Cuerpo/Arte /Sociedad. Buenos Aires: Ed. Letra Viva-UBA, 2006a. 165-179.

Aschieri, Patricia. "Trabajo de campo y metamorfosis: Los cuerpos del etnógrafo". Ponencia presentada en el VIII Congreso Argentino de Antropología Social: 2006. Simposio: Una antropología de y desde los cuerpos, 2006b.

Aschieri, Patricia. “Entre Buda y Rodin. Entre Buda y Rodin: Traducciones culturales en los cuerpos de la Danza Butoh Argentina.," En Aschieri y Citro, comps. Cuerpos en Movimiento. Perspectivas interculturales sobre el movimiento y la danza. Buenos Aires: Editorial Biblos, 2012.

Aschieri, Patricia "Subjetividad en movimiento. Reapropiaciones de la danza butoh en Argentina". Tesis doctoral en Antropología. Universidad de Buenos Aires. Buenos Aires: Facultad de Filosofía y Letras, 2013a.

Aschieri, Patricia. “Hacia una etnografía encarnada: La corporalidad del etnógrafo/a como dato en la investigación" Ponencia presentada en la X Reunión de Antropología del MERCOSUR. Situar, actuar, imaginar antropologías desde el Cono Sur. Universidad Nacional de Córdoba. Córdoba. Argentina 10-13 de julio, 2013b.

Aschieri, Patricia y equipo. "Movimientos de significación en torno a 'lo oriental' en la formación de bailarines, actores y performers: un estudio de caso", Revista Publicar. Buenos Aires: Colegio de Graduados de Antropología, 2012.

Barba, Eugenio y Nicola Savarese.comp. Anatomía del Actor. México: Gaceta/ International School of Theatre Anthropology, 1988.

Bhabha, Homi. El lugar de la cultura. Manantial, Buenos Aires, 2002 
Bataille, Georges. Le masque. París: Gallimard, 1970.

Bernard, Michel. El cuerpo: un fenómeno ambivalente. Buenos Aires: Paidós, 1994.

Bizerril, José. O retorno à raiz. Uma linhagem taoísta no Brasil. São Paulo: Attar Editorial, 2007.

Bourdieu, Pierre. El sentido práctico. Madrid: Taurus. 1991

Citro, Silvia. “El Cuerpo emotivo: del ritual al teatro", En Matoso, Elina, comp. Imagen y representación del cuerpo. Serie Ficha de Cátedra, Teoría General del Movimiento. Buenos Aires: Publicaciones de la Facultad de Filosofía y Letras Universidad de Buenos Aires, 2001. 19-34.

Clifford, James. Dilemas de la cultura. Antropología, literatura y arte en la perspectiva posmoderna, Barcelona: Gedisa, 2001.

Csordas, Thomas. Somatic Modes of Attention. Cultural Anthropology. Vol 8. núm 2, 1993, 135-156.

Feldenkrais, M. Autoconciencia a través del Movimiento - Ejercicios para el desarrollo personal. Buenos Aires: Paidós, 1980.

Fischer-Lichte, Erika. “Las tendencias interculturales en el teatro contemporáneo" En Pavis Guy Rosa, comp. Tendencias Interculturales y Práctica escénica. México: Gaceta, 1994.

Gadamer Hans Geror. "La historicidad de la comprensión como principio hermenéutico". Verdad y Método. Fundamentos de una hermenéutica filosófica. Ediciones Sígueme. Salamanca, 1991.

Greiner, C. (2005). "O colapso do corpo a partir do ankoku butô de Hijikata Tatsumi" http://www. japonartesescenicas.org

Jameson, Frederich El posmodernismo o la lógica cultural del capitalismo avanzado. Barcelona: Paidós, 1991.

Jung Carl. Psicología y Alquimia. Plaza Yanes Editores. S.A, 1989.

Hannerz, Ulf. Conexiones transnacionales. Cultura, personas, lugares. Madrid: Ediciones Cátedra, 1998.

Horton Fraleigh, Sondra. Dancing into Darkness Butoh, Zen and Japan. USA: University of Pitsburg Press, 1999.

Kassai, Toshiharu y Parsons Kate. "Perception in butoh dance", Memories of the Hokkaido, Institute of Technology. Vol. 31, 2003. 257-264.

Lecoq, J El cuerpo poético. Una pedagogía de la creación teatral. Alba Editorial, 2005.

Levi-Strauss, C. La vía de las máscaras. México: Siglo veintiuno editores, 1997.

Lizarazo, María Camila. “Lo grotesco en el butoh. Recobrando la humanidad perdida". Monografía de estudios teatrales. Universidad de los Andes. Bogotá: Facultad de Artes, 2000. www. japonartesescenicas.org

Neumannova, Radka. "Multiculturalism and cultural diversity in modern nation", Conference Turin University of Economics, Prague Czech Republic: 2007.

Matoso, Elina. El cuerpo, territorio de la imagen. Buenos Aires: Letra Viva, 2001

Macfie, Alexander. Orientalism a reader. Edimburgo: Edimburgo University Press, 2000.

Merleau-Ponty, Maurice. Fenomenología de la Percepción. Península, 1975.

Mauss, Marcel. "Las técnicas del cuerpo" y "La noción de persona", En Sociología y Antropología, Madrid: Tecnos, 1979. 309-336 y 337-356.

Osinski Zbigniew. "Grotowski blazes the trails: from objective drama to ritual arts". The Drama Review 35, 1991.

Pradier, Jean. "Ritología de las emociones", Revista Conjunto, núm 101, La Habana Cuba, 1995. 3-10.

Pavis, Patrice. El análisis de los espectáculos. Teatro, mimo, danza, cine. Barcelona: Editorial Paidós, 2000. 
Pavis, Patrice y Rosa, Guy. Tendencias Interculturales y Práctica Escénica. México: Gaceta, 1994.

Rodinson, Maxime. La fascinación del Islam. Barcelona: Ed. Jucar, 1989.

Rosenberg, Nancy. "Dialectic Balance in the Polar Model of Self: The Japan Case", Ethos, Vol. 17, núm 1 1989, 88-113.

Said, Edward. Orientalismo. España: Debate, 2002.

Sato, Amalia. “Máscaras", Revista Ventizca. Edición Invierno y Junio. Buenos Aires, 2008, 22-24.

Schechner, Richard. “El interculturalismo y la elección de la cultura”, En Pavis Guy Rosa, comp. Tendencias Interculturales y Práctica escénica. México: Gaceta. 1994.

Shayegan, Dayrush. La Luz viene de Occidente. Barcelona: Tusquets, 2008.

Svampa, Maristella. “El Populismo Imposible y sus actores 1973-1976". En Nueva Historia Argentina, 1955-1976, Volumen IX. Buenos Aires: Sudamericana, 2003. 381-437.

Torres Molina Susana. Entrevista Latin American Theatre Review. Spring, 2002.

Turner, Bryan. Orientalism, postmodernism and globalism. Nueva York: Routledge, 1994.

Turner, Victor y Bruner, Edward, eds. The Anthropology of Experience. Urbana and Chicago: University of Illinois Press, 1986.

Turner, Terence. "Anthropology and Multiculturalism: What Is Anthropology That Multiculturalists Should Be Mindful of It?" Cultural Anthropology, Vol. 8, núm. 4. (noviembre 1993), 411-429.

\section{Cómo citar este artículo:}

Aschieri, Patricia. “Maquillar los cuerpos / transmutar en movimiento: Reflexiones acerca de las reelaboraciones de la danza butoh y sus máscaras". Cuadernos de Música, Artes Visuales y Artes Escénicas, 10 (1), 95-113, 2015. http://dx.doi.org/10.11144/ Javeriana.mavae10-1.mctm 
